\title{
EL LÉXICO DEL MAR EN COSTA RICA: ANÁLISIS GEOLINGÜÍSTICO (1)
}

\author{
Randi Korneliussen
}

\begin{abstract}
RESUMEN
El presente artículo es el producto de una investigación geolinguística realizada en localidades situadas en las costas atlántica y pacífica de Costa Rica, en donde la principal fuente de trabajo es la pesca. El trabajo consta de 43 mapas lingüísticos puntuales y está dividido en dos partes. En la primera parte -que es la presente- figuran los marcos teórico y metodológico del estudio, además de los primeros 17 mapas lingüísticos. En la segunda parte se mostrarán los 26 mapas lingüísticos restantes, acompañados de una interpretación lingüístico-etnográfica.

Palabras clave: Léxico del mar, Costa Rica, mapas lingüísticos y etnográficos, análisis dialectológico.
\end{abstract}

\begin{abstract}
The present article describes and analyses the vocabulary used by fishermen and sailors in Costa Rica, such as tasks related to the sea and the act of fishing. The linguistic material was gathered along the Caribbean and Pacific coasts by means of a geolinguistic field work. This is the first part of an article presenting 43 punctual linguistic maps. The theoretical frame and the first 17 maps are included in this issue, whereas the last 26 maps, followed by a linguistic interpretation, will be published in the next edition of this review.

Key Words: Terms of the Sea, Costa Rica, linguistic and etnographic maps, dialectological analysis.
\end{abstract}

\section{Introducción}

Los atlas lingüísticos suelen dedicar una parte a los marinerismos. Se puede mencionar como ejemplo el ALEICan, en el que gran parte del tercer tomo (120 páginas con mapas analíticos y lingüístico-etnográficos, y además dibujos con nombres) trata el tema del mar y los seres marinos. En 1977, se publicó Terminología marinera del Mediterráneo, de Manuel

Randi Korneliussen. Licda. en Filología Española e Inglesa. Profesora en el Colegio Oystese Gymnas y en el Colegio Técnico de Norheimsund, Noruega. Mediadora de conflictos en la region de Hordaland.

Correo electrónico: rankodyret@hotmail.com

Recepción: 20-5-04

Aceptación: 24-5-04 
Alvar. Este trabajo da una lista con transcripciones, pero no incluye mapas. José Joaquín Montes publicó en 1973 un estudio llamado Muestra del léxico de la pesca en Colombia. De menor escala es El léxico del pescador en Puerto Armuelles (Cáceres y Palacios 1980). Esta publicación trata una zona panameña cercana a Costa Rica, por lo que es particularmente relevante para la presente investigación.

La meta general del presente trabajo es llevar a cabo una investigación geográfico-lingüística sobre el léxico marinero de las costas atlántica y pacífica de Costa Rica. Esto abarca tanto el vocabulario usado para nombrar los fenómenos meteorológicos y las características geográficas de estas zonas, como el léxico relacionado con las actividades pesqueras y marineras. Los objetivos específicos son los siguientes:

1. Presentar el vocabulario recopilado en mapas lingüísticos que muestren su distribución geográfica ${ }^{1}$.

2. Interpretar el material para determinar zonas dialectales costeras, y compararlas con la división establecida anteriormente por Agüero (1962) y Quesada (1992b).

3. Contribuir con la realización del Atlas Linguiístico-etnográfico de Costa Rica.

\section{Esbozo teórico}

Los postulados teóricos que han dado base a la presente investigación giran en torno a la disciplina lingüística conocida como geografía linguiística o geolingüística, tal como figura explicada y analizada en Coseriu (1985), Alvar (1969), Montes Giraldo (1970).

El objeto de estudio de la geografía lingüística es la realidad viviente del habla en el funcionamiento de una lengua dentro de las diversas regiones de su extensión y, recientemente, en los diversos niveles sociales (cfr. Thun 1990). La meta principal de esta disciplina es la elaboración de atlas lingüísticos. Un atlas lingüístico pretende ofrecer un cuadro vívido y verdadero de la vida efectiva del lenguaje (Montes Giraldo 1970: 72-3). Además, muestra la distribución geográfica de elementos lingüísticos de un dialecto o una lengua, mediante mapas lingüísticos. Incluye una serie de mapas sobre el mismo territorio; uno para cada concepto lingüístico, al contrario de los atlas geográficos corrientes, cuyos mapas representan diferentes territorios físicos (Coseriu 1985: 111). De acuerdo con Lope Blanch (1975: 127-30),

\footnotetext{
(...) son el instrumento más sistemático, homogéneo y -tal vez- económico para descubrir y presentar el estado en que se halla, en un momento determinado y en su estructura general, cualquier sistema lingüístico.
}

Los atlas dan una vista panorámica sobre fenómenos lingüísticos y "una observación general acerca del funcionamiento del lenguaje" (Coseriu 1985: 114). Sin embargo, también tienen sus limitaciones. Gerhard Rohlfs observa que:

\footnotetext{
los atlas lingüísticos jamás podrán constituir la fuente única de nuestro conocimiento del lenguaje regional. Hay una inmensidad de elementos lingüísticos que por una u otra razón escaparán siempre a las encuestas realizadas para un atlas lingüístico (cit. por Montes 1982: 65).
}

Los mapas muestran, por lo general, una sola dimensión de la lengua. Las variedades culturales y las diferencias de prestigio social entre sinónimos no se distinguen muy bien con el sistema tradicional. 
A partir de los años 20, creció en Alemania (Meringer) y Rumania (Schuchardt) la conciencia sobre el valor y la necesidad de relacionar el campo lexicográfico con la etnografía. La escuela de Wörter und Sachen no considera solo el léxico en sí, sino también la realidad denotada por este, viendo la lengua como un reflejo del ambiente que expresa (Current Trends in Linguistics 1963, tomo IX: 236). Esto ha dado resultados fructíferos sobre todo en los estudios de actividades primarias, como la pesca y la agricultura. Las palabras para el léxico del mar, por ejemplo, están íntimamente relacionadas con la realidad etnográfica de los hablantes. Si se consideran las preguntas 95 y 123 de este trabajo, sobre los diferentes tipos de arpones y redes que se usan en Costa Rica (ver los mapas 34 y 42), se da información adicional a las meras palabras, sobre el mundo de los informantes; se dan indicaciones sobre el grado de industrialización, qué especies de animales marinos hay, etc. Efectivamente, el mismo Alvar utiliza en sus atlas, por ejemplo en ALEA y ALEICan, tanto mapas etnográficos que combinan la distribución lingüística de las palabras con dibujos de los objetos, intentando "establecer las áreas de las "realia" (M. Alvar 1975: nota preliminar), como mapas exclusivamente lingüísticos que responden a los planteamientos onomasiológicos.

Por las limitaciones de una investigación como la presente, la relación entre palabras y cosas en este caso se manifiesta únicamente en los mapas lingüístico-etnográficos anteriormente mencionados y en su interpretación. Esto facilita, sin embargo, estudios posteriores sobre el léxico del mar y la etnografía correspondiente.

\section{Marco metodológico}

El presente estudio se basa en el habla de 43 informantes de 16 localidades de Guanacaste, Puntarenas y Limón, que son las tres provincias costarricenses con línea costera. Personalmente llevé a cabo entrevistas con 33 personas en 12 localidades entre enero y abril de 1997. Se habían encuestado además a 10 informantes en siete lugares a priori, entre 1993 y 1995, la mayoría por Arturo Quesada Aguilar.

\subsection{Las localidades}

Los puntos de referencia fueron elegidos con base en su distribución geográfica, para cubrir con espacios regulares toda la línea costera del país, donde se supone que el conocimiento sobre el vocabulario del mar es más grande. También hay lugares situados cerca de ríos con actividad pesquera. Se visitaron 13 localidades en el Pacífico (Cuajiniquil, Playa del Coco, Tamarindo, Garza, San Francisco de Coyote, Puerto Moreno, Calle del Arreo, Puntarenas, Quepos, Ciudad Cortés, Puerto Jiménez, Golfito y Paso Canoas) y tres en el Caribe (Barra del Tortuguero, Puerto Limón y Puerto Viejo) ${ }^{2}$. Se dio importancia a los sitios que mostraban diferencias etnográficas entre sí, siendo este uno de los factores que podrían influir en el lenguaje. Hay representados pequeños pueblos aislados, como Barra del Tortuguero, y puertos grandes, por ejemplo, Puntarenas. Al elegir localidades, se tomó además en cuenta las características de los sitios visitados. 


\subsection{Los informantes}

De los 43 informantes registrados, había 29 pescadores, 4 marineros, y 7 cuyo trabajo también tenía relación con el mar y la pesca: tres indican como profesión "administrador de cooperativa de pesca"; uno, "vendedor de pescado"; uno, "comerciante de mariscos"; uno, "trabajo propio"; y uno, "carpintero de ribera"3. Los hablantes con otras ocupaciones eran pertinentes por su interés y conocimiento del tema que nos ocupa. Siete personas tenían ocupaciones adicionales.

La gran mayoría (27 personas) tenía entre 30 y 50 años de edad en el momento de la entrevista (primer semestre de 1997). Sólo ocho tenían menos de 30 años, y seis más de $50^{4}$. Optaba por informantes jóvenes o de edad media. Comparados con los mayores, y conforme Jud y Jaberg, en general resultaban ser más abiertos en cuanto a las respuestas que se buscaban. También se mostraban más pacientes y atentos durante la entrevista, que duraba aproximadamente dos horas. Mi objetivo era registrar el léxico del mar en general, y no, como en muchos casos, el de rescatar un vocabulario en extinción. Esto me permitía utilizar informantes en distintas etapas de la vida, sin poner énfasis en el rasgo "edad avanzada". En caso de no coincidir el lugar de la entrevista con el de nacimiento, siempre me aseguraba de antemano de que los informantes hubieran vivido muchos años en el sitio, la mayoría desde muy temprana edad. Sobre todo en sitios pequeños fue difícil encontrar hablantes adecuados nacido en el lugar.

Veintidós hablantes tenían educación primaria (en parte o completa) ${ }^{5}$. Sólo ocho tenían educación más alta que la primaria, de los cuales uno había ido a la universidad. En adición a los informantes mencionados, hay algunos sin registrar ${ }^{6}$, que eran participantes de entrevistas de grupo en Garza, Puntarenas, Puerto Moreno y Golfito.

En algunos sitios me informé en el pueblo o pregunté en la playa para conseguir contacto con hablantes adecuados. Si el pueblo tenía una cooperativa o estación receptora de pesca, solía buscar estas. Me facilitó mucho preguntar a los informantes de un lugar por contactos en el siguiente. Siempre estuvieron muy dispuestos a ayudarme con nombres y de esta manera se iba desarrollando una red de contactos en el camino. En algunos sitios, las personas de referencia ya me estaban esperando, pues habían sido avisadas por sus colegas en las localidades anteriores. En la costa atlántica, me acompañó un pescador limonense que servía como puente entre los hablantes y yo.

De entrada había calculado al menos dos informantes por localidad ${ }^{7}$. No obstante, resultó insuficiente en ciertas ocasiones. En sitios de convergencia y cerca de las fronteras nacionales, el número de informantes es mayor; en el primer caso, para captar y reflejar la gran variedad en el habla de los habitantes, y en el segundo, para ampliar el material y aumentar la información lingüística en áreas con probable influencia dialectal entre países vecinos. En los sitios donde se realizaron entrevistas colectivas, la cantidad de informantes también fue mayor.

En la lista con los datos de los hablantes (tabla 1), los nombres de los diez informantes no entrevistados por mí van en letra cursiva, y la información no obtenida se marca con [-]. 

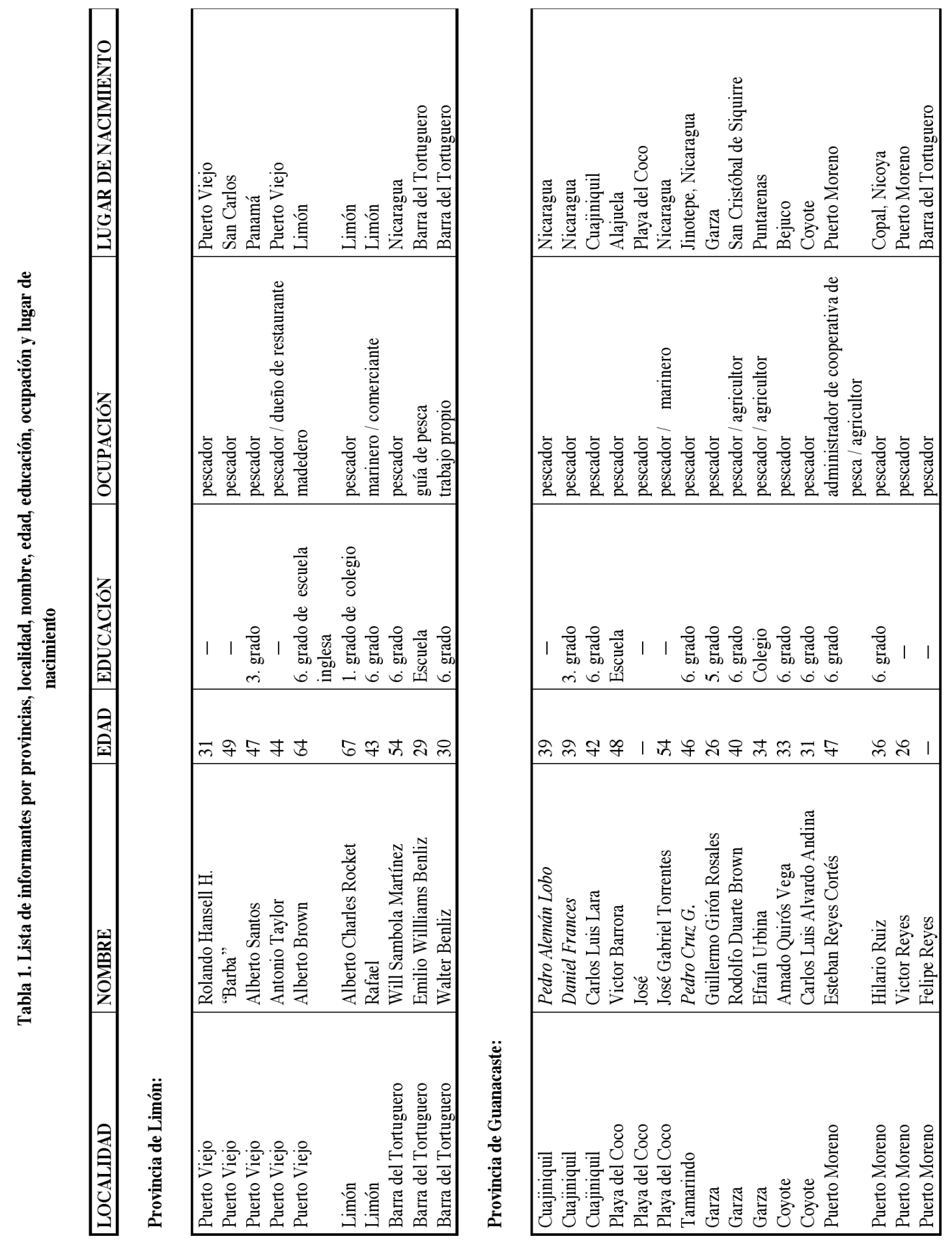


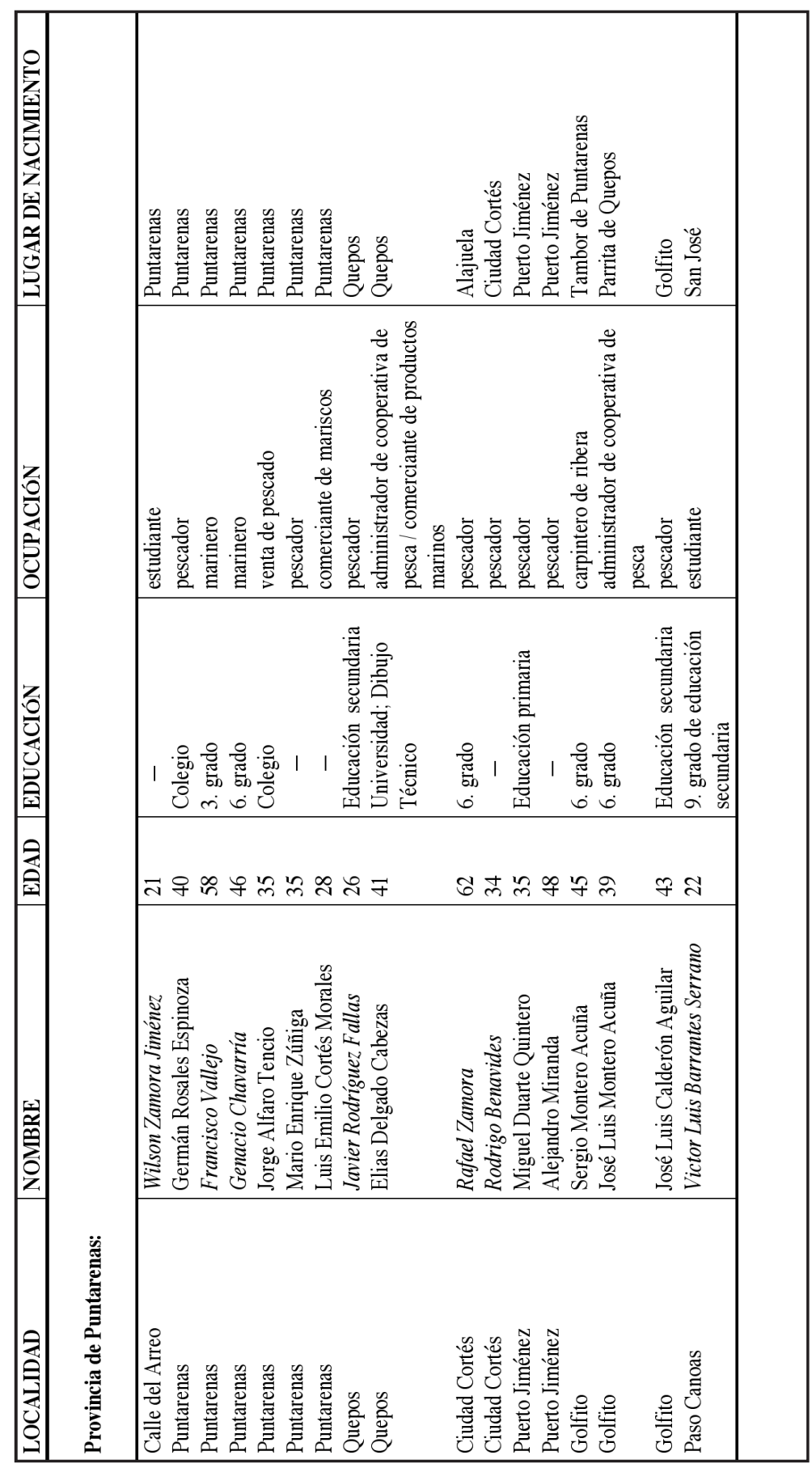




\subsection{El cuestionario}

Para la recolección del material, se utilizó el cuestionario del Atlas lingüístico de Costa Rica (Quesada Pacheco 1992) ${ }^{8}$. En dicho cuestionario, el léxico del mar pertenece a un subgrupo llamado El hombre en su ambiente social, y consiste en 131 preguntas directas e indirectas, entre las cuales se encuentran varias del tipo múltiple 9 . Como no se puede esperar una respuesta simple, estas preguntas son difíciles de manejar, ya que la falta de unicidad aumenta la posibilidad de malos entendidos. Opté por conservar la mayor parte, no obstante, porque son muy útiles para reflejar diferencias etnográficas entre las zonas dialectales. Efectivamente, uno de los objetivos señalados por Quesada Pacheco (ibid.: 9) es "hallar particularidades lingüísticas y etnográficas que estén condicionadas geográficamente".

Las modificaciones que he hecho son las siguientes: se han quitado la pregunta 68, por ser difícil de manejar; la 70, por su poca actualidad en el habla de los informantes; y la 125, que es en realidad una repetición de la 92. Se han depurado también las preguntas 126 - 130, sobre especies de peces y mariscos. Como no disponía de fotos o grabados para mostrar a los informantes, habría sido complicado distinguir un tipo de animal de otro.

\subsection{Las entrevistas}

Se realizaron encuestas directas, normalmente con una persona a la vez, en la casa del informante o en otro sitio tranquilo. En algunos lugares, como en Puerto Viejo y Playa del Coco, hablé con los pescadores en la playa mientras trabajaban. En San Francisco de Coyote, los dos informantes estaban juntos, hablando conmigo y entre sí al mismo tiempo. Otra variante de entrevistas colectivas se hizo en Garza, Puerto Moreno, Puntarenas y Golfito, donde fui a las cooperativas y conversé con varios informantes a la vez.

Las entrevistas individuales generalmente gozaron de más tranquilidad que las colectivas, pero estas también resultaron ventajosas. Al discutir el vocabulario entre ellos, los informantes revelaron distinciones y variaciones del uso que probablemente no habrían sido descubiertas de otra manera. Donde las preguntas requerían respuestas con explicaciones más específicas, por ejemplo, dibujos de anclas o presentaciones de redes, barcos, etc., uno o más informantes siempre complementaron eventuales lagunas con la información adecuada, con tranquilidad, después de la entrevista colectiva ${ }^{10}$. Una entrevista en grupo duró aproximadamente tres horas y media, dos o más individuales entre cuatro y seis horas en total, y cada una alrededor de dos horas.

\subsection{Los mapas}

La mayoría de los mapas son del tipo mixto, donde las respuestas son representadas por números, letras o palabras. Las voces se organizan alfabéticamente, pero siempre con variantes del mismo lexema o frase juntas, con subdivisiones numeradas (ver por ejemplo el mapa 8, en el que cirial y cirio se consideran variaciones de la misma palabra (e1 y e2)). Las estructuras perifrásticas sinónimas se subclasifican según uno o más elementos de la frase. En el mapa 11, por ejemplo, todas las combinaciones con ir y una variante de costear están juntas; lo mismo 
cuenta para frases con navegar más orilla, y navegar en combinación con la raíz cost-. Una respuesta siempre aparece en un sólo grupo, aunque en algunos casos podría, por su forma, pertenecer también a otros. Este es el caso para el verbo costear (ver mapa 11), que en lugar de b1, se podría haber clasificado como h1. El hecho de subdividir las respuestas contribuye a hacer los mapas más ordenados y facilita su análisis. Esto vale sobre todo para los mapas con frases verbales, donde suele haber variantes lingüísticas muy parecidas.

Los mapas lingüístico-etnográficos se distinguen de los puramente lingüísticos en varios aspectos, el más llamativo es el hecho de que contienen dibujos. Mientras que los mapas puramente lingüísticos ponen énfasis en el léxico, los mapas etnográficos dan importancia también al objeto, y las palabras se organizan según la cosa que denota.

Cada ilustración va acompañada de una lista de los nombres que se usan en los diferentes sitios. Cada objeto es representado por un número, y cada nombre por una letra ${ }^{9}$. En el mapa $34 \mathrm{~A}$, por ejemplo, todos los nombres que figuran bajo el punto 1 representan el mismo tipo de red. $l a, b, c, d$ y $e$ son voces sinónimas, pero con diferente distribución geográfica. En los mapas etnográficos no se destinguen subnumeraciones entre variantes del mismo lexema.

En vista de que el criollo es sobre todo una lengua oral, y de que, además, en la zona atlántica se domina el inglés normativo, en el presente trabajo se dan las voces criollas transcritas en inglés estándar; de esta manera, se evitará la necesidad de establecer un límite artificial entre el continuo que existe entre los dos idiomas.

\section{Mapas lingüísticos y etnográficos}


Filología y Lingüística XXX (2): 171-203, 2004
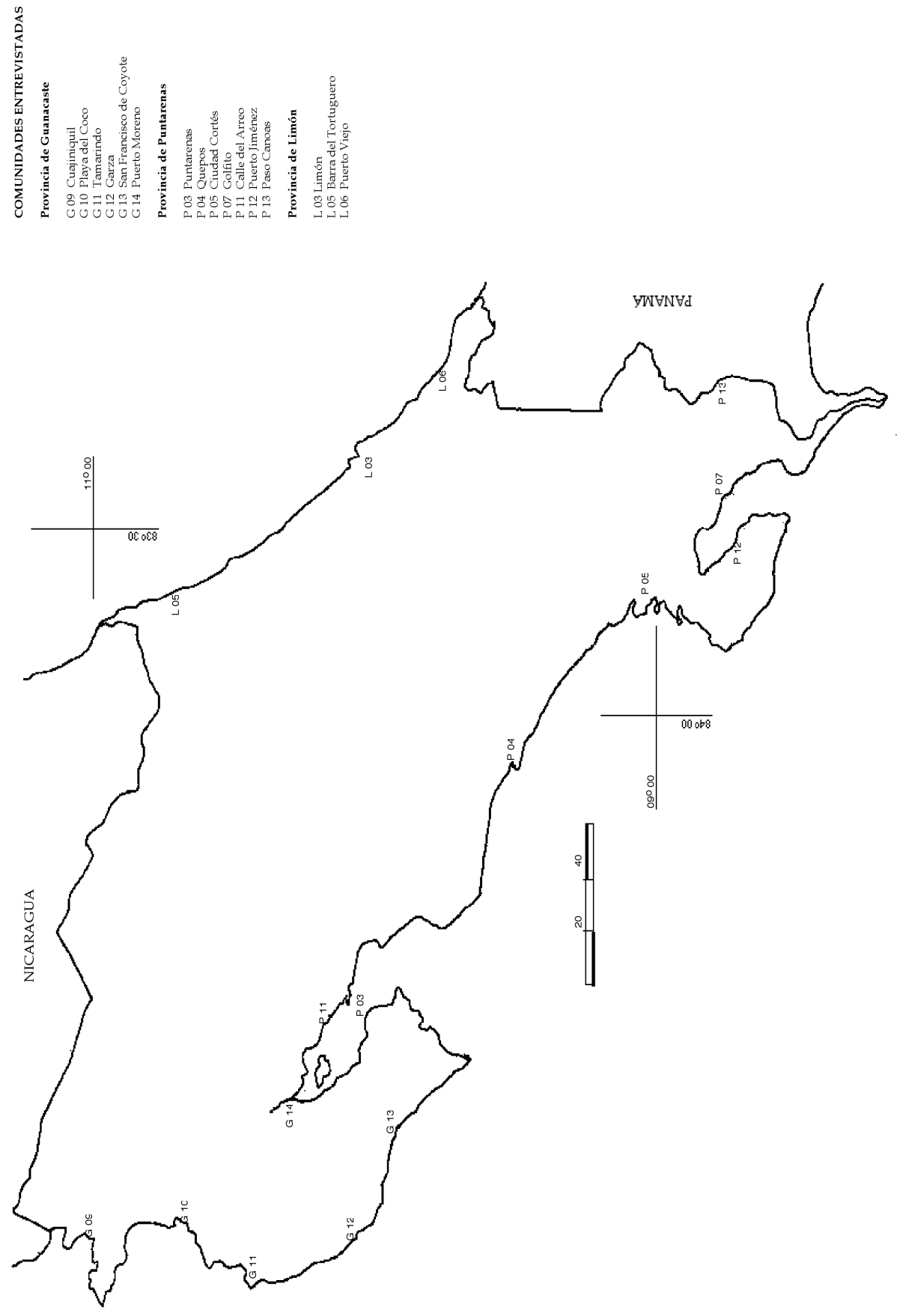

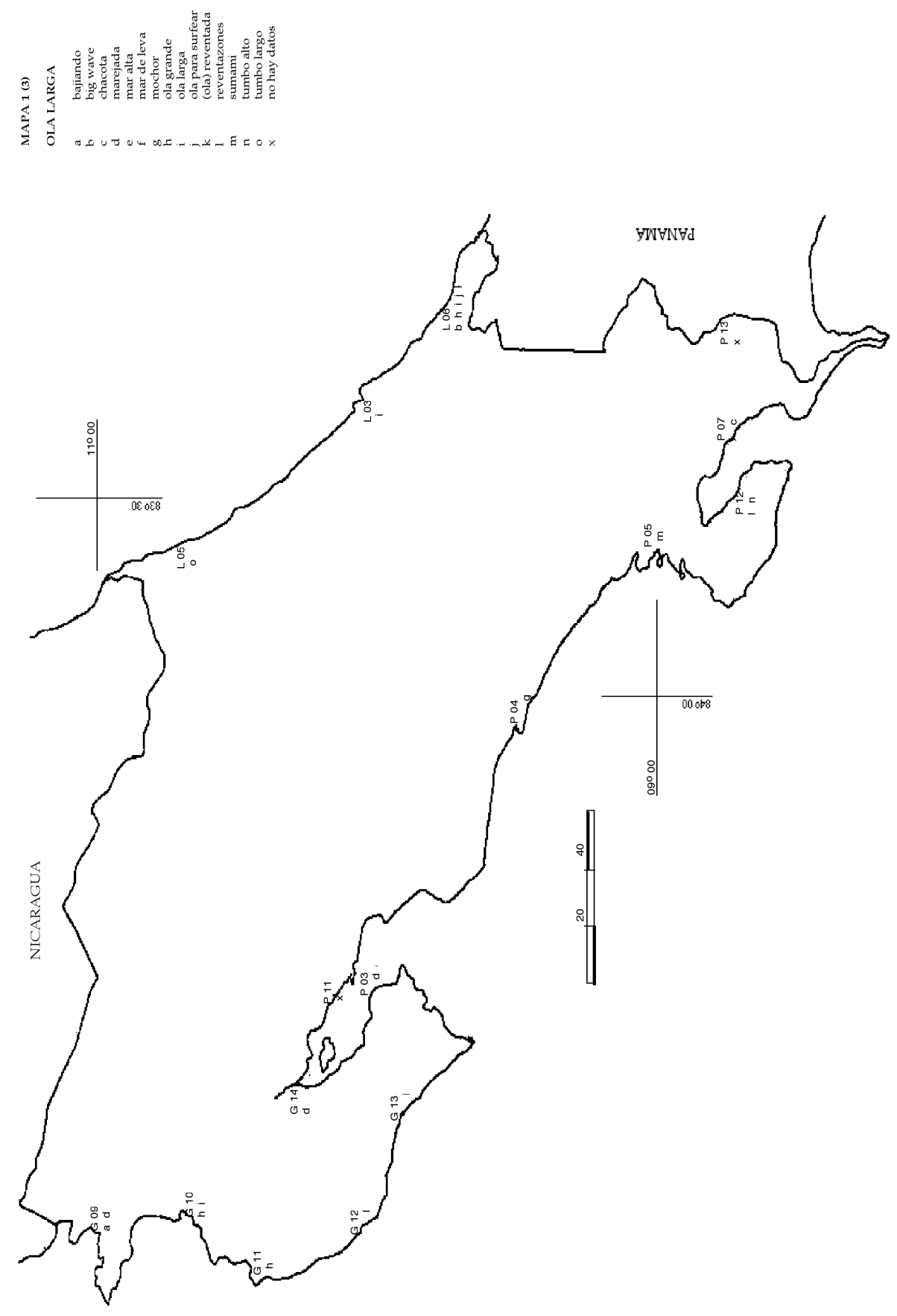

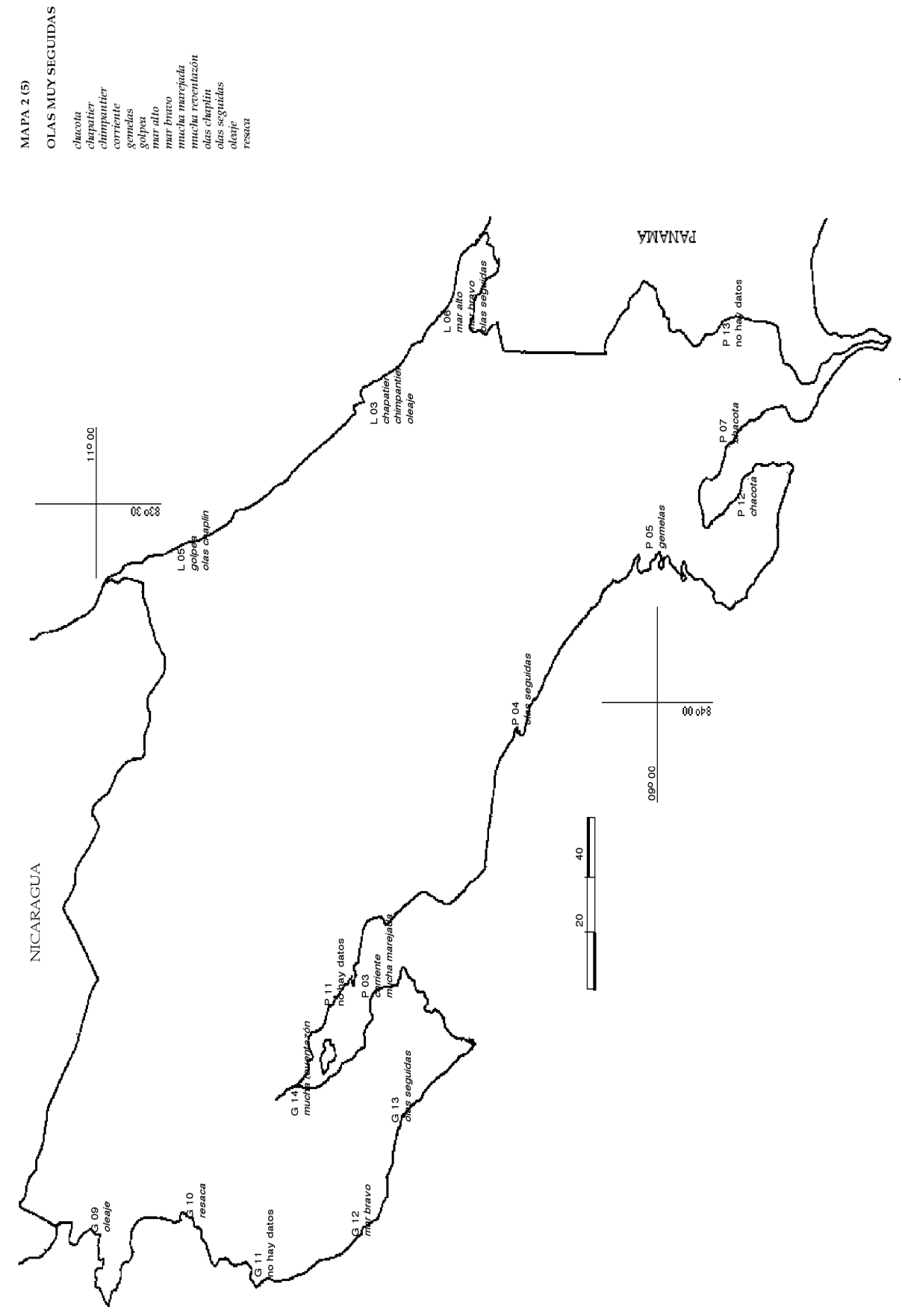

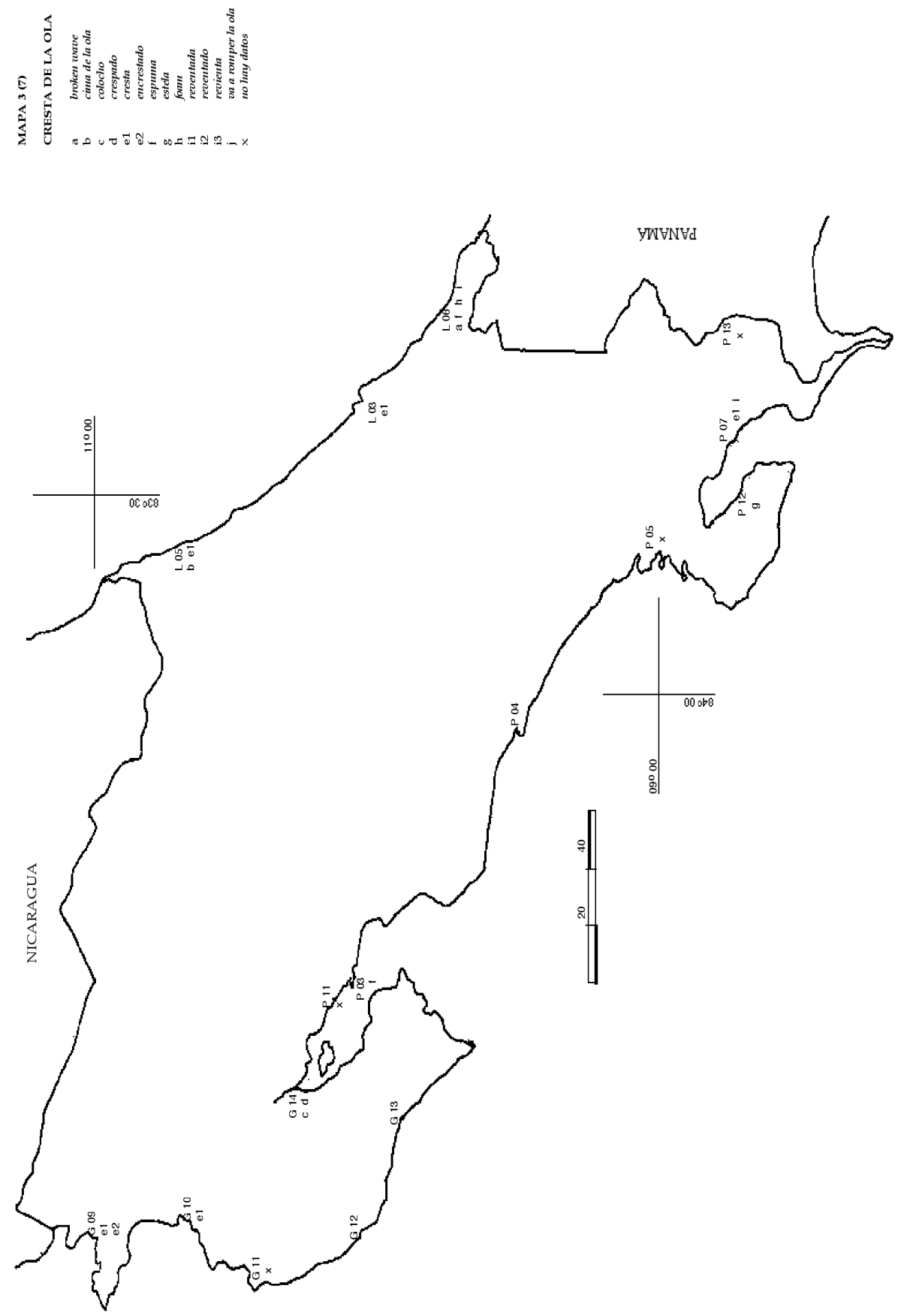
II thitul

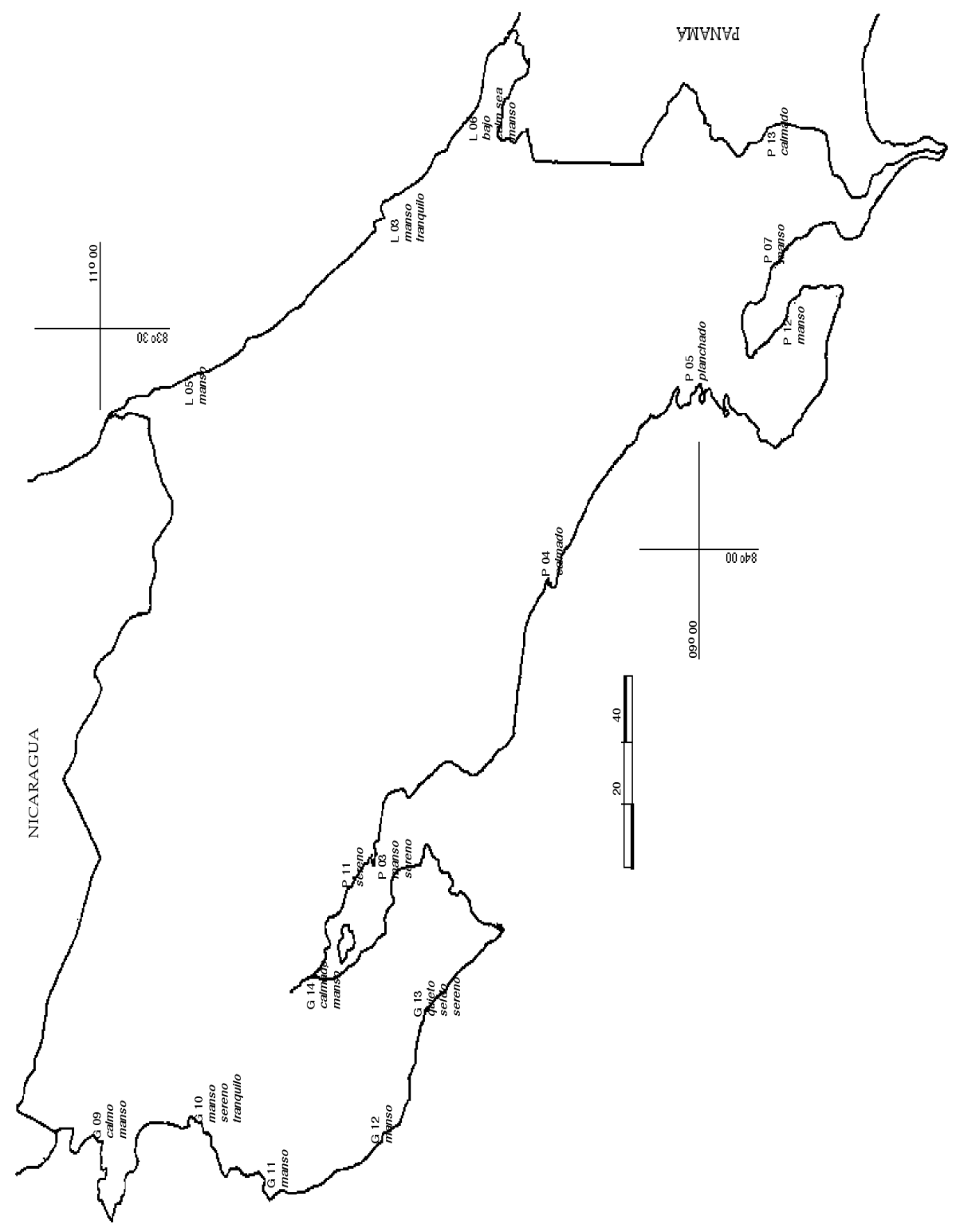



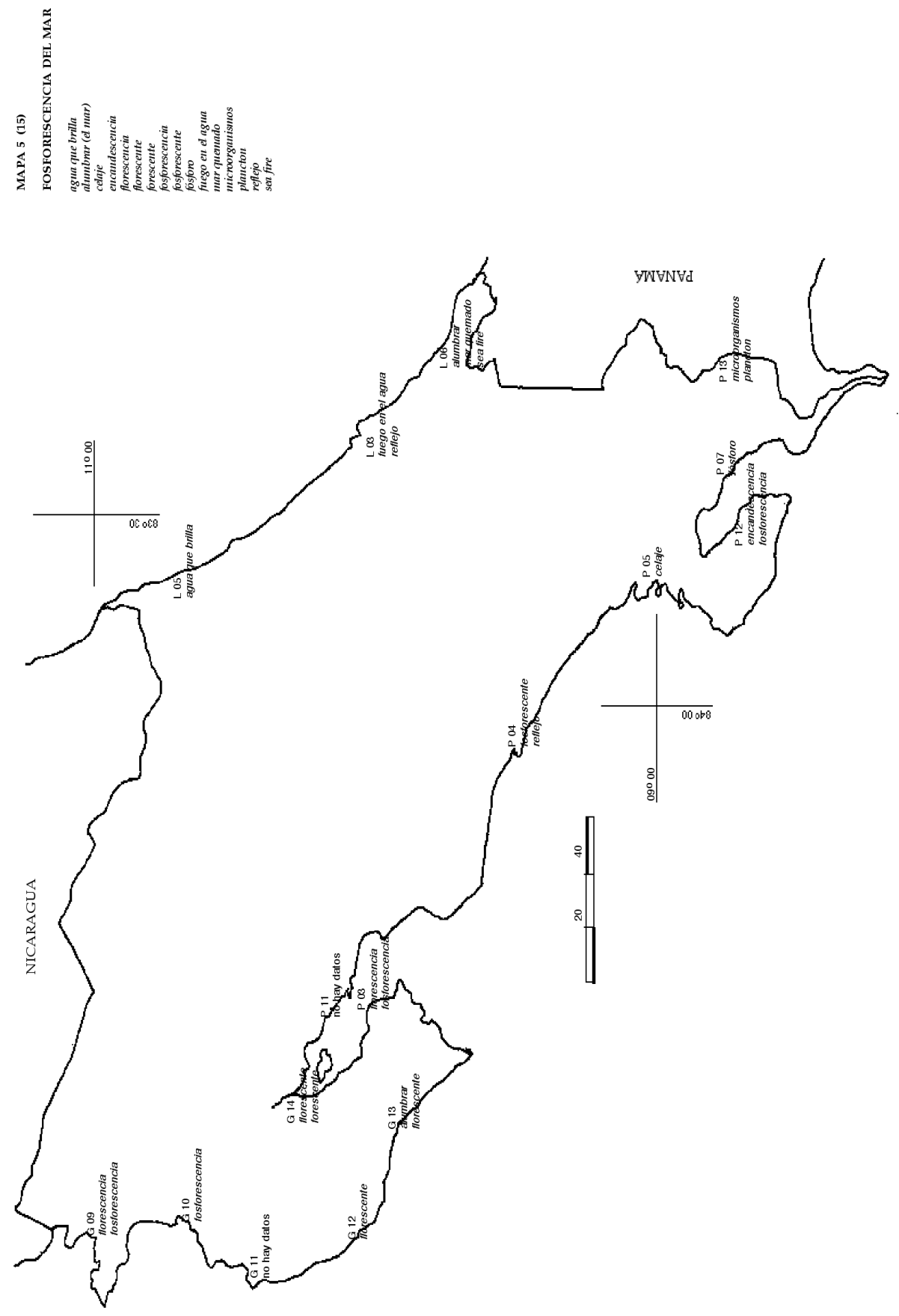


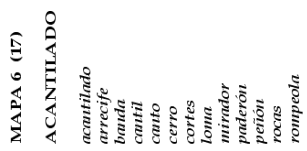

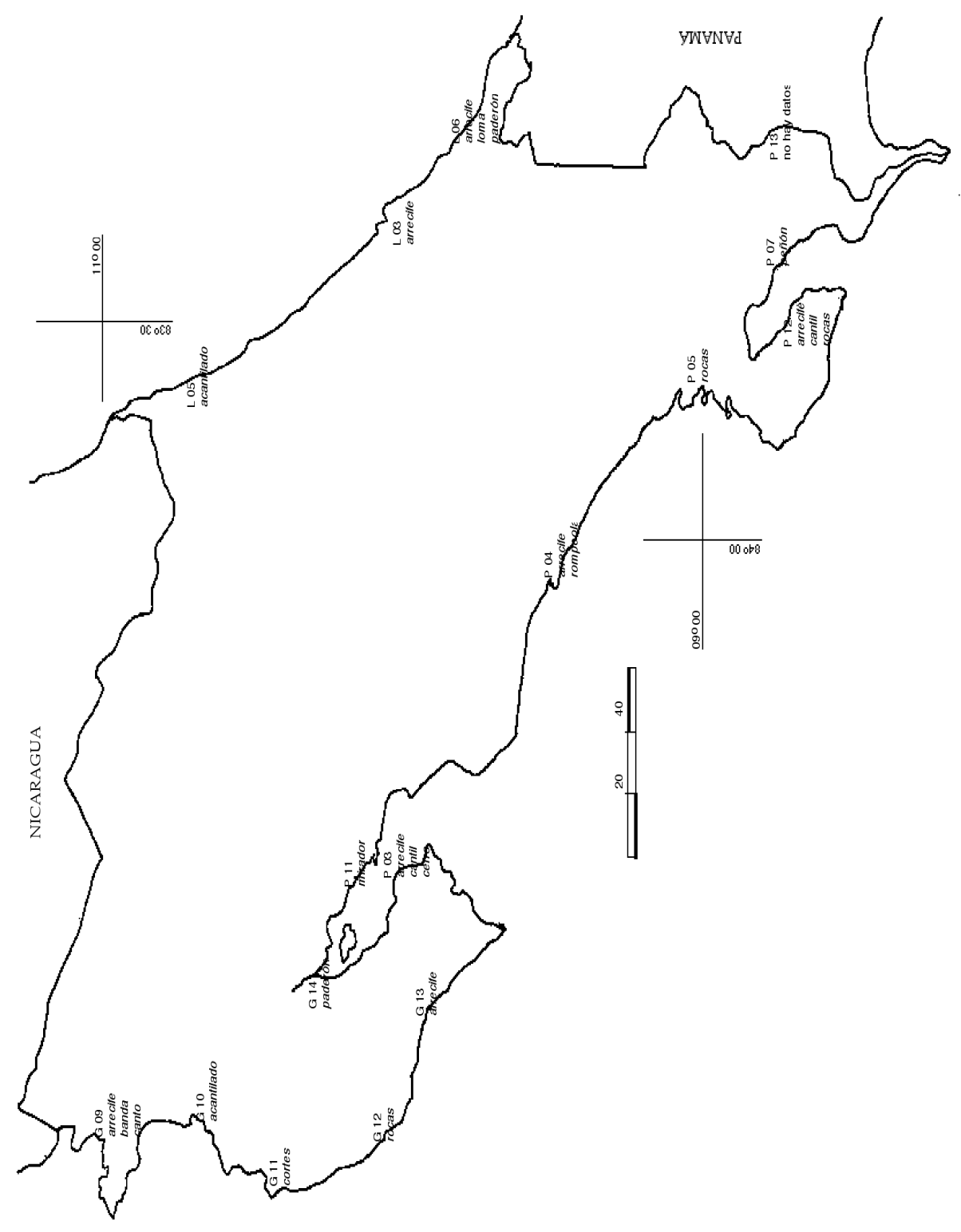



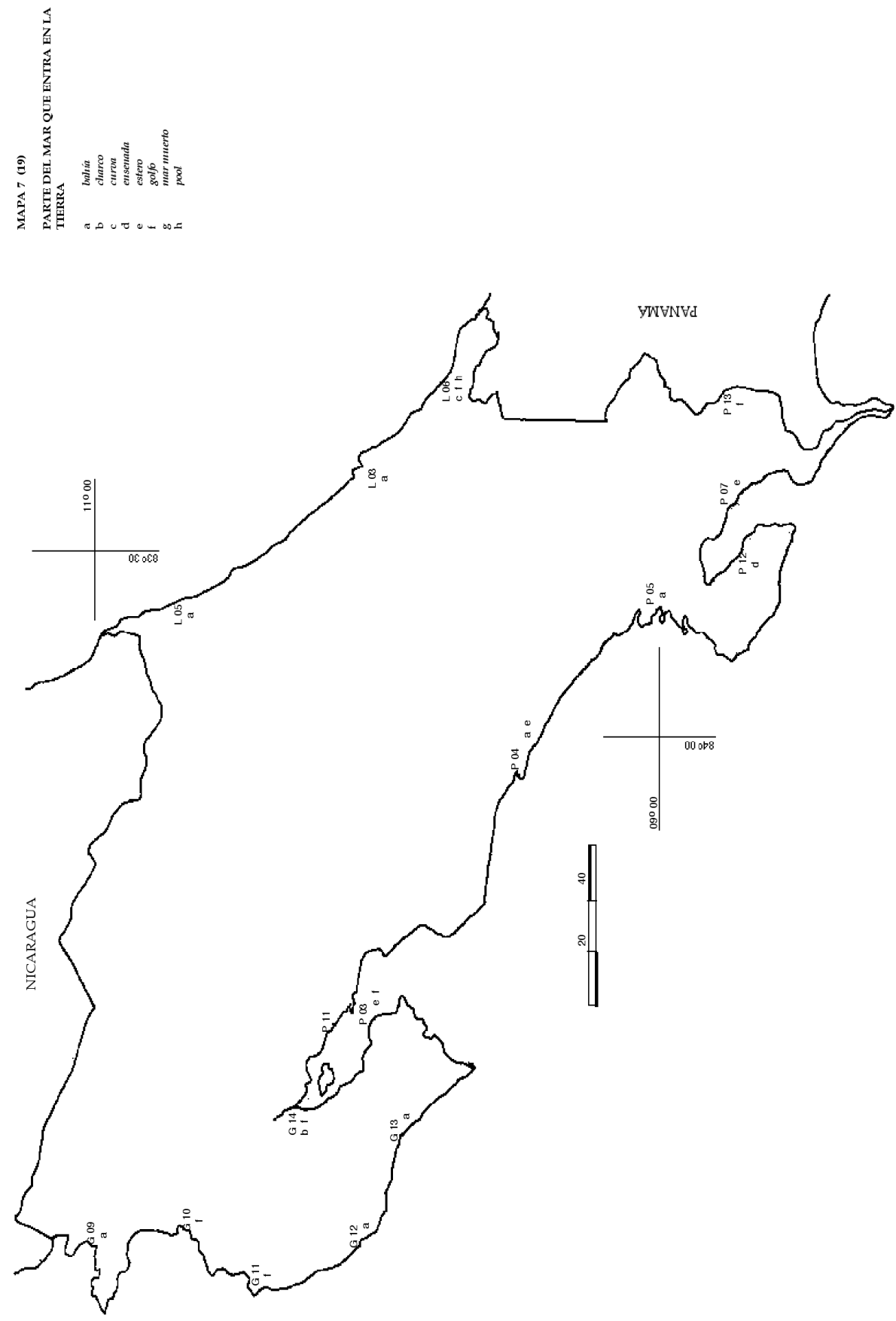

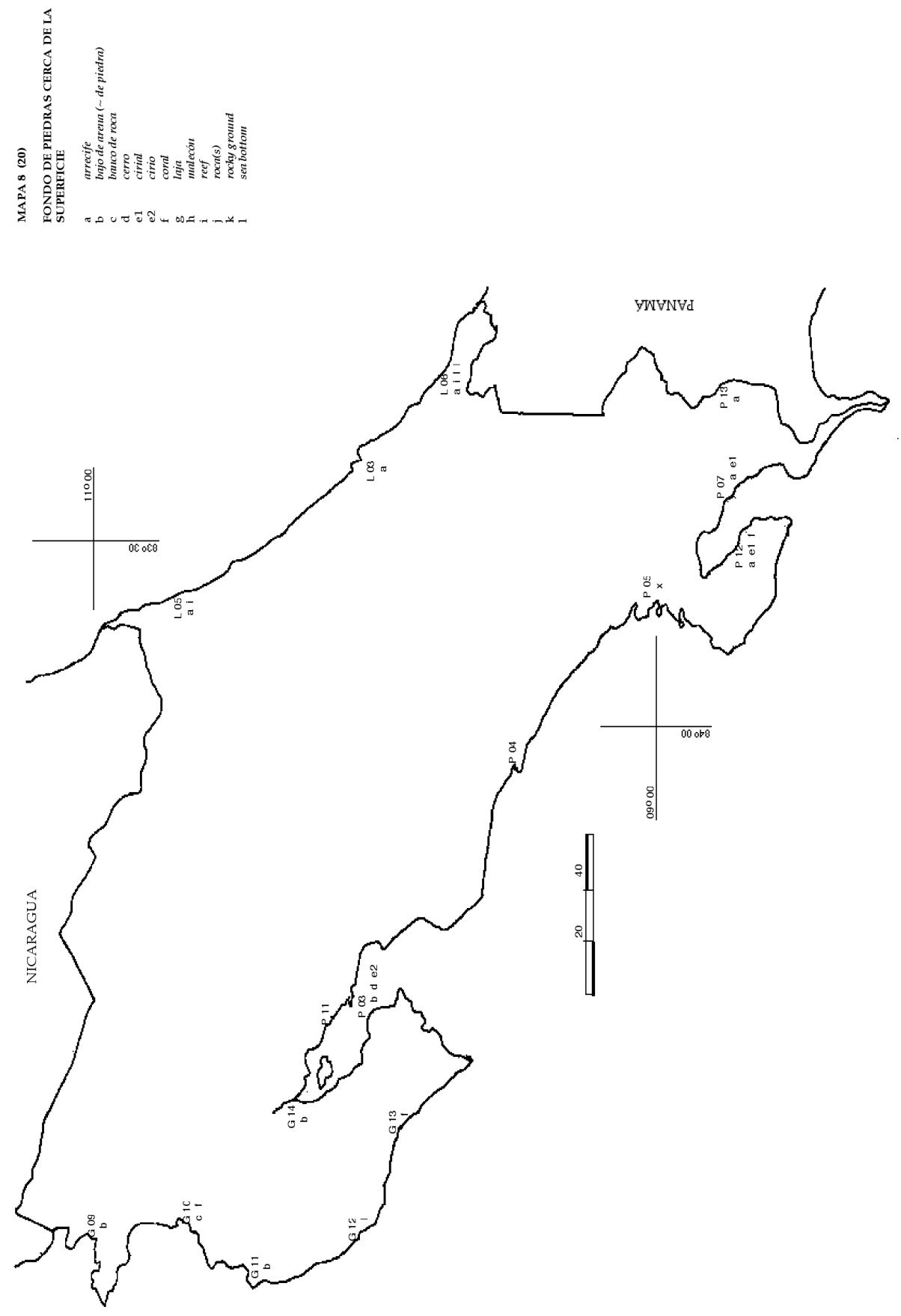

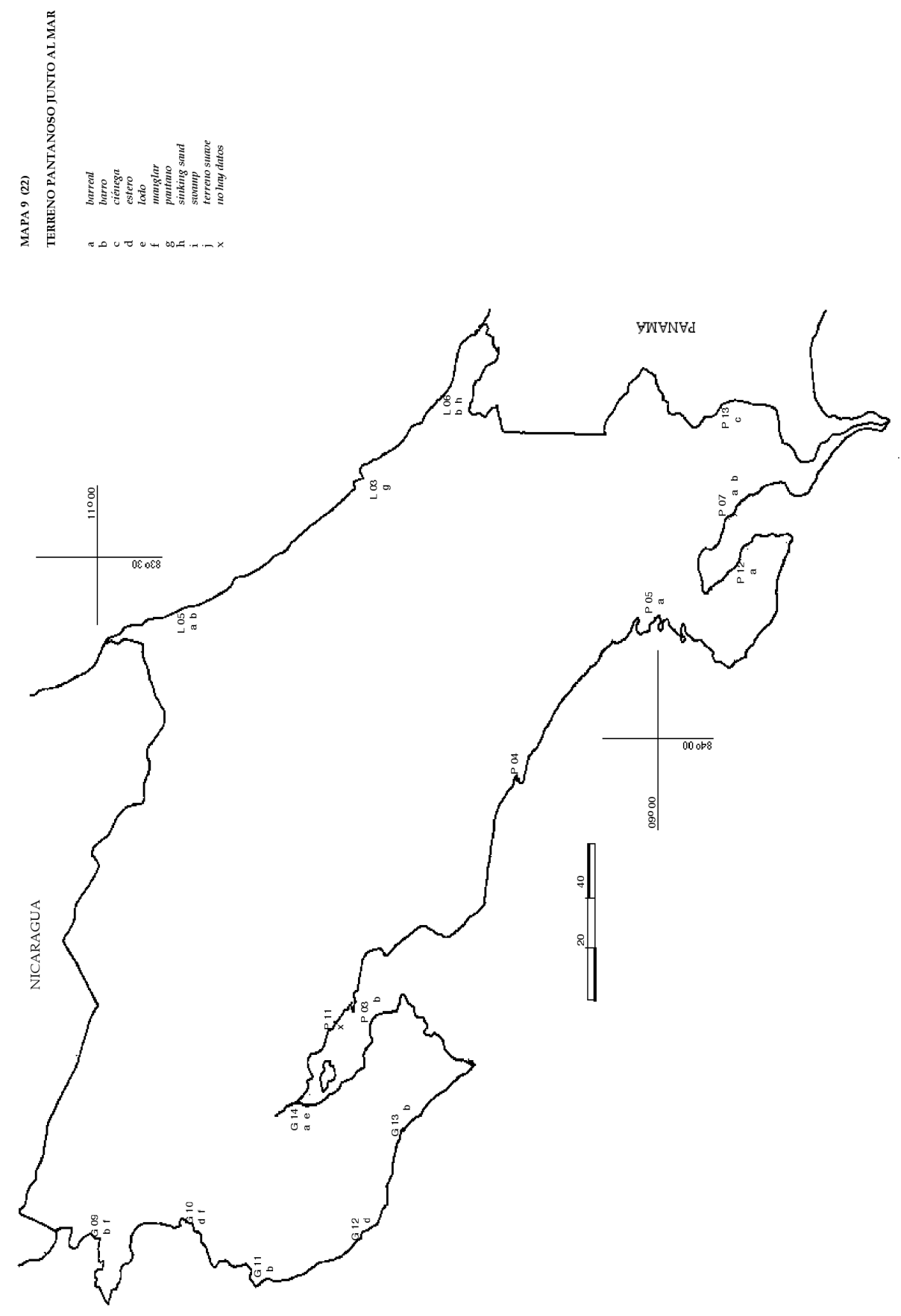

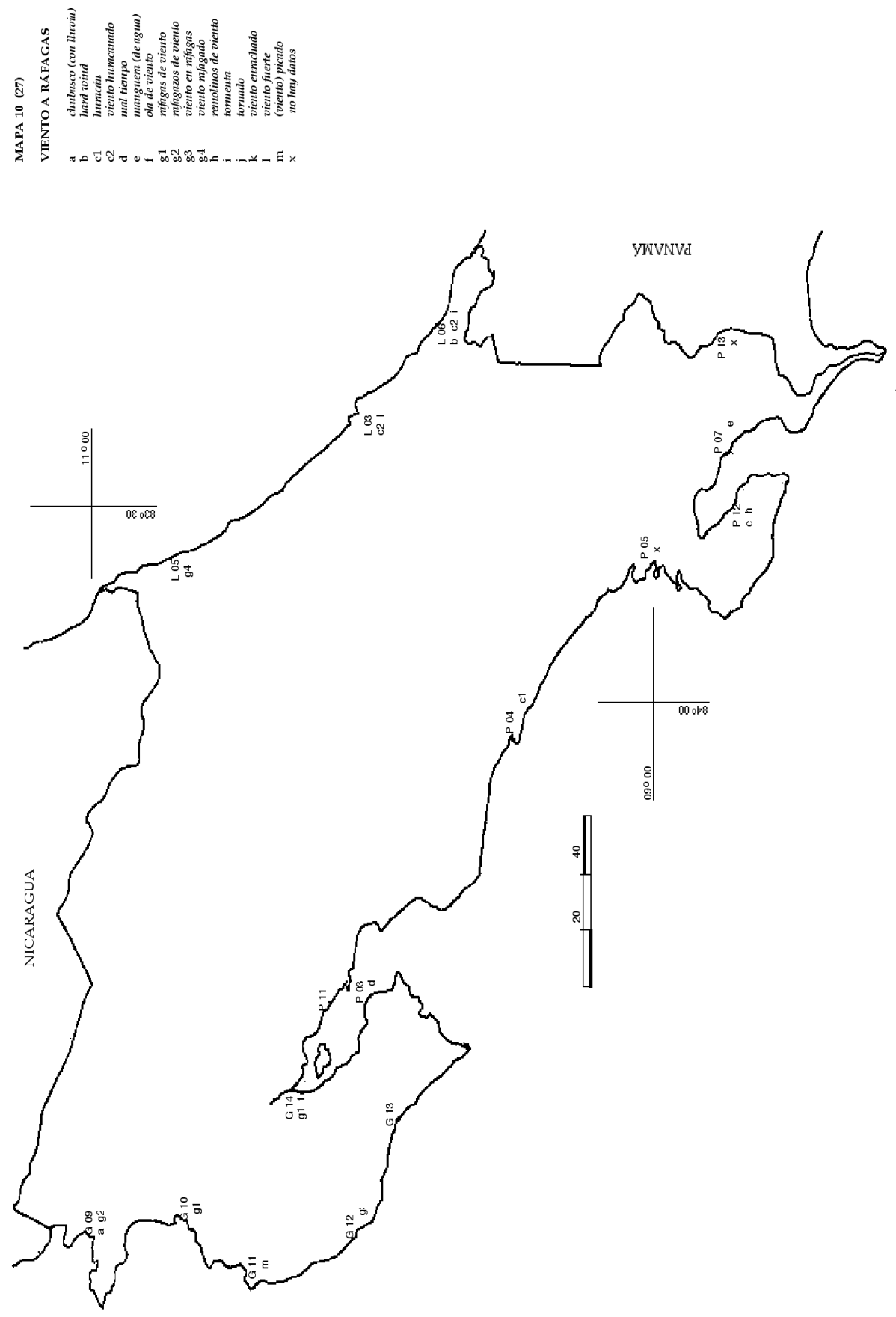

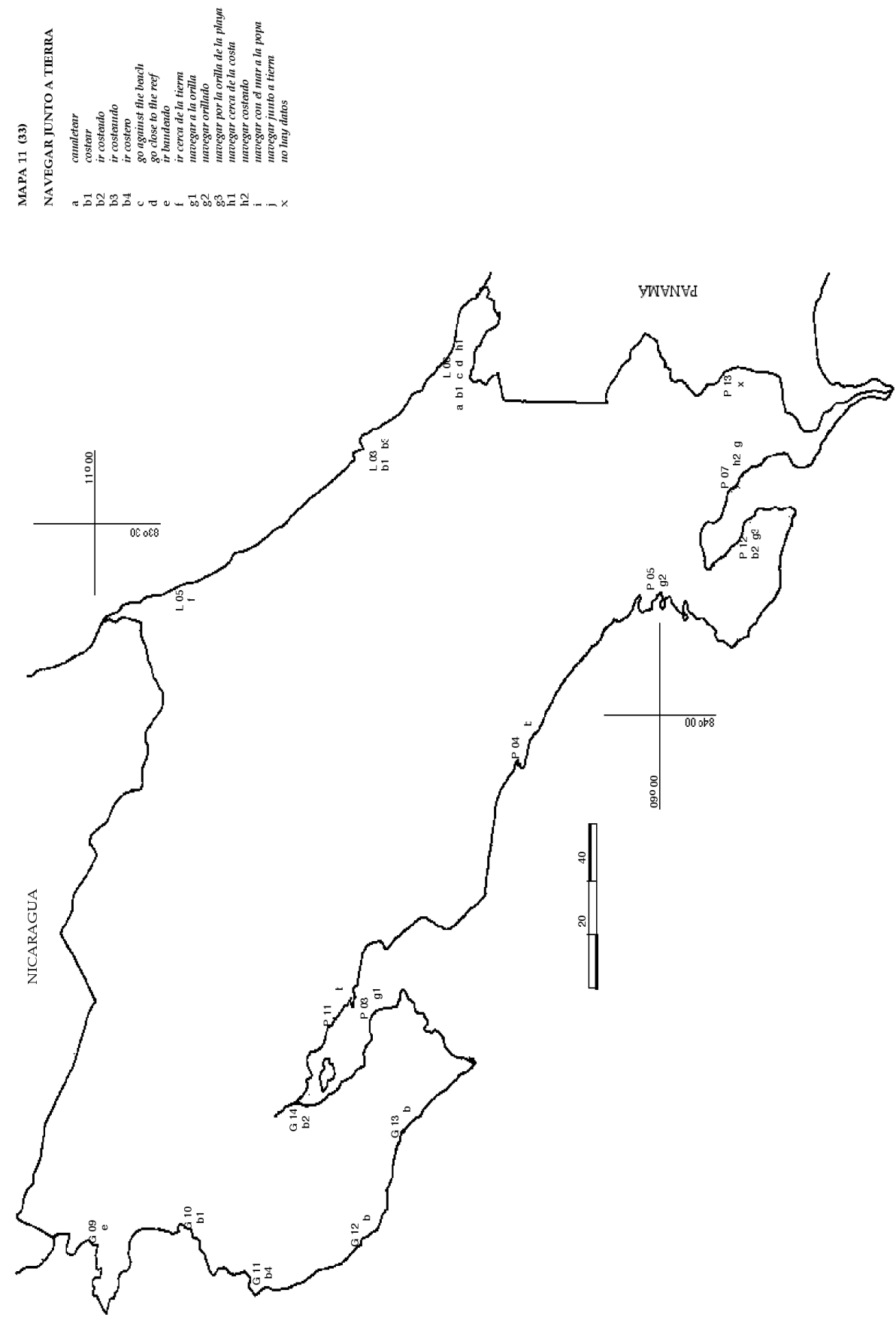

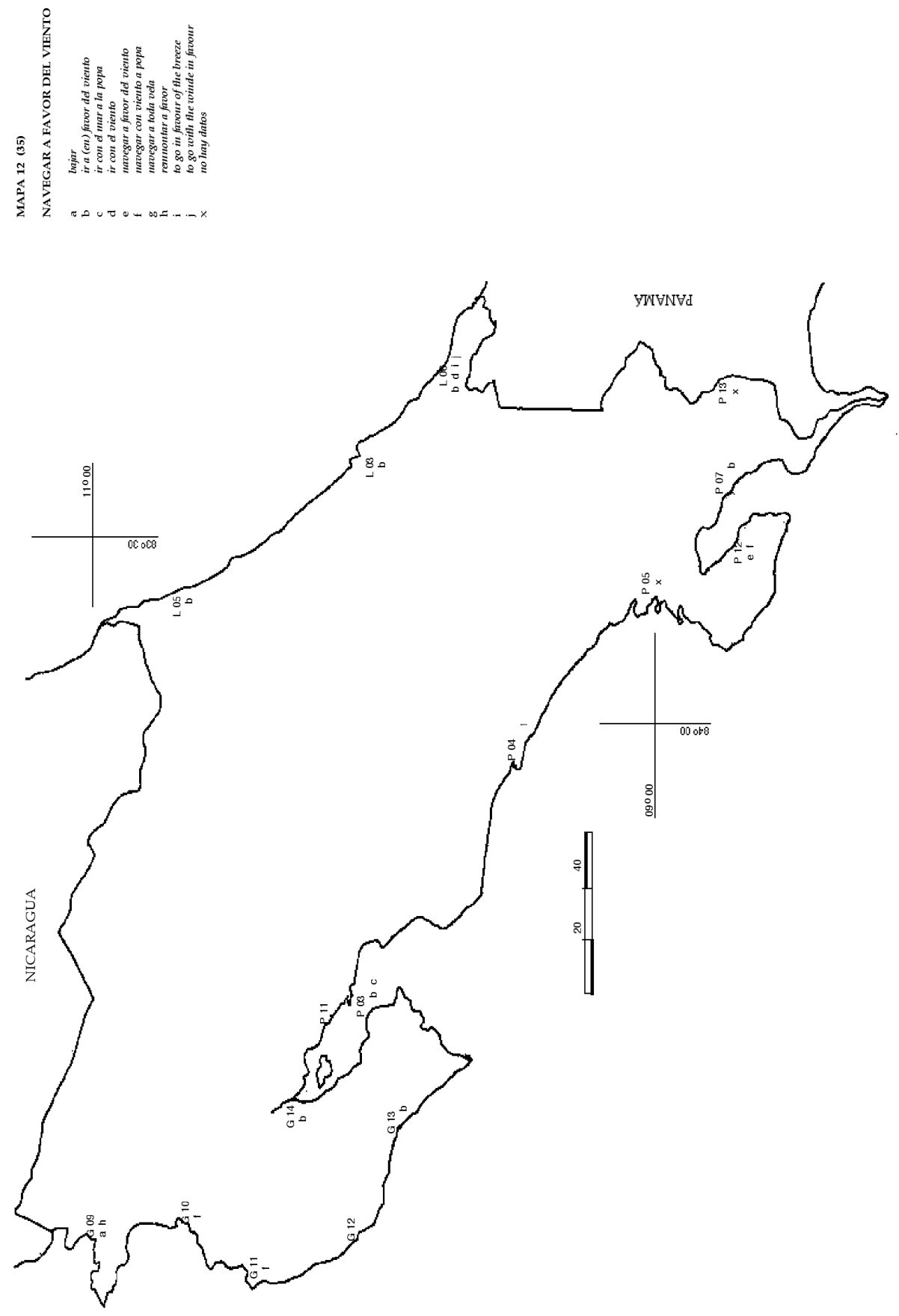

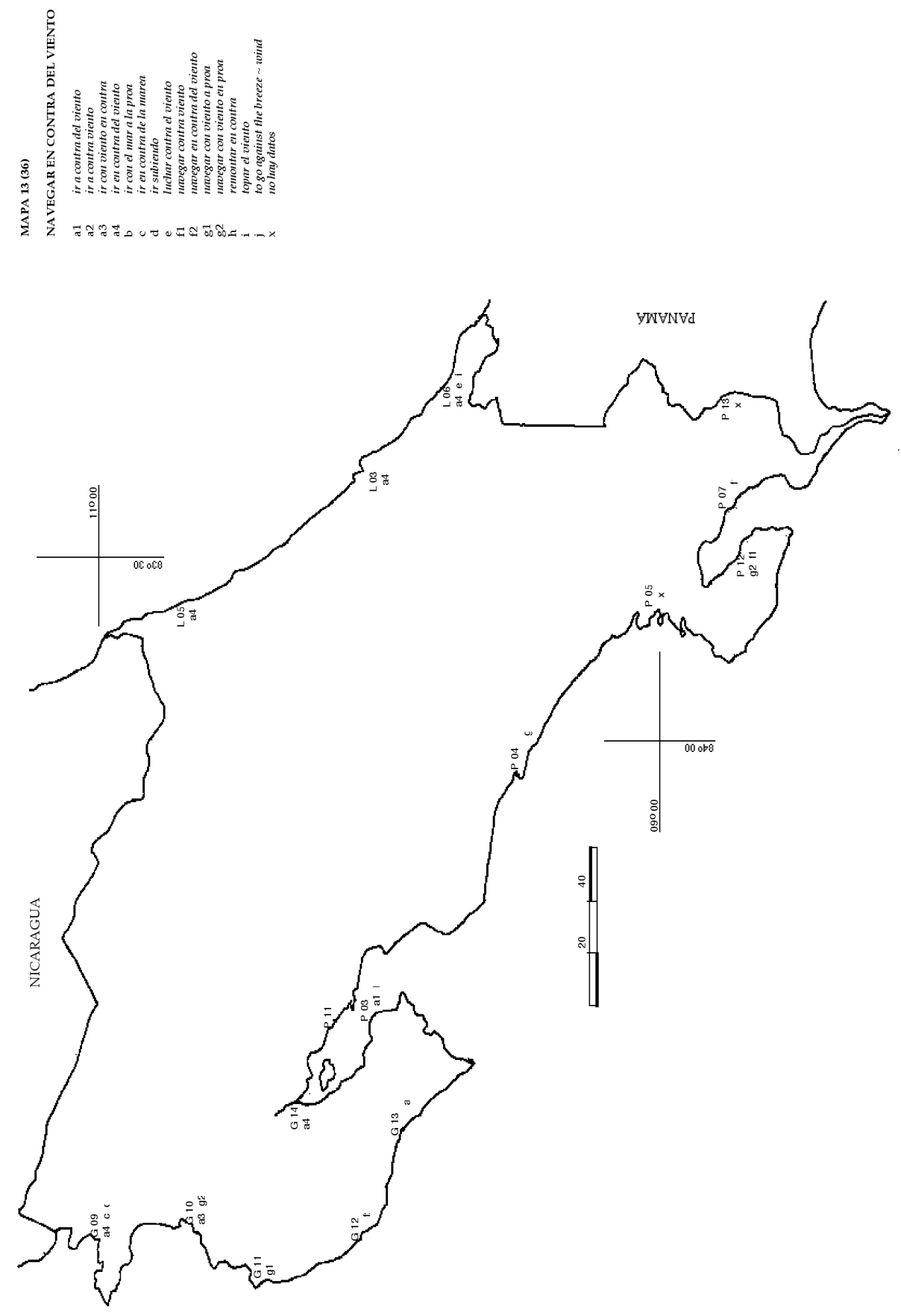

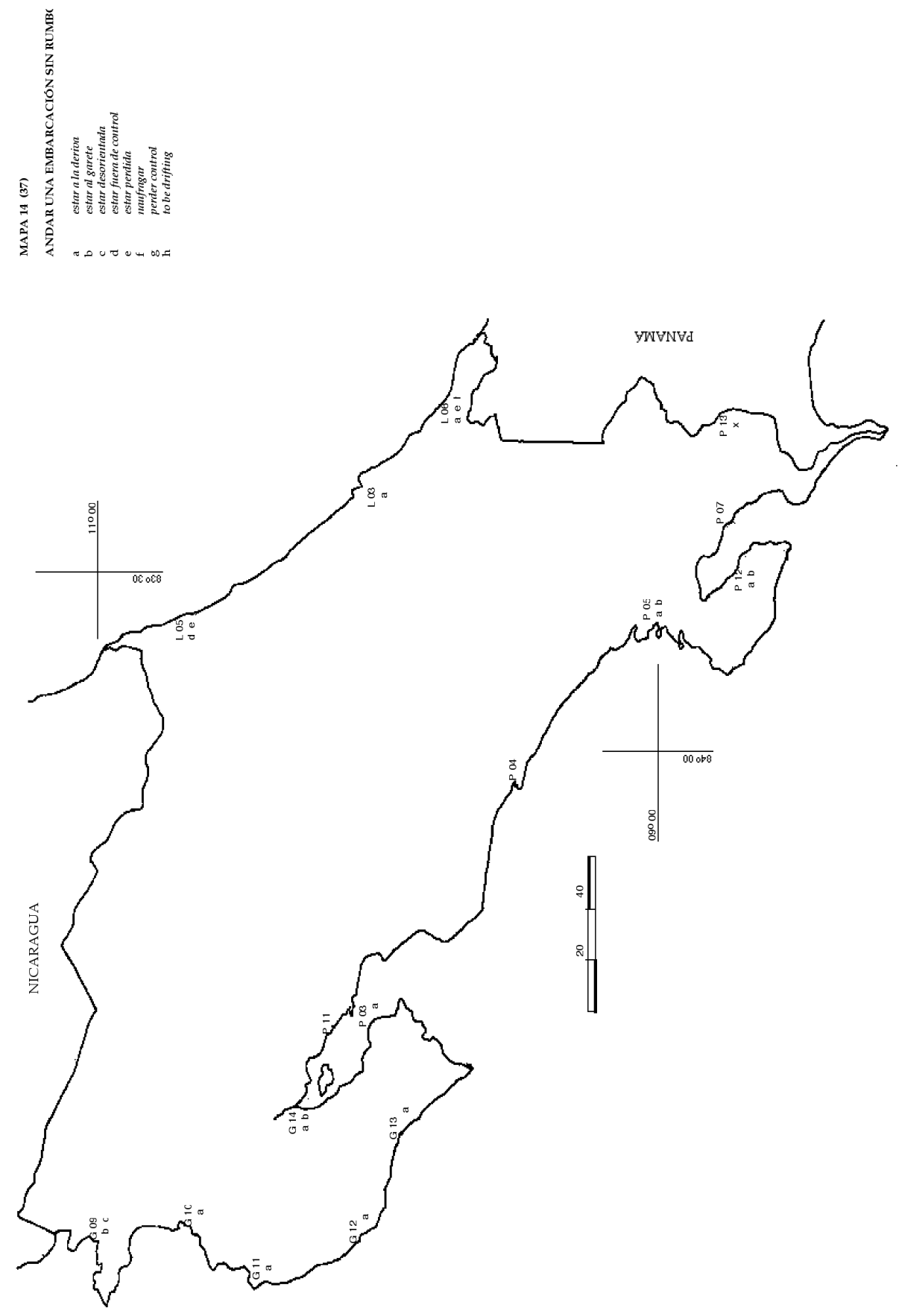

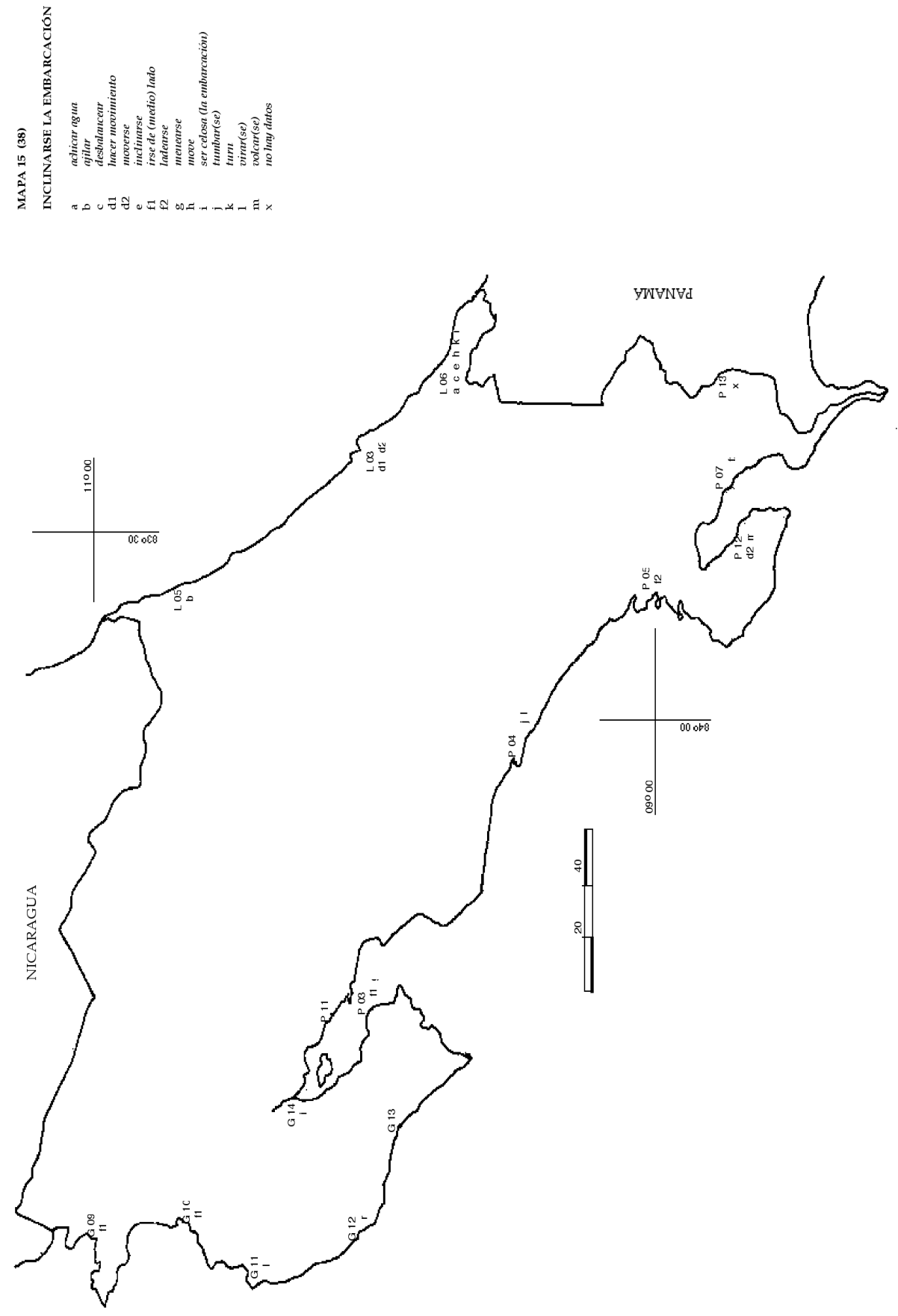

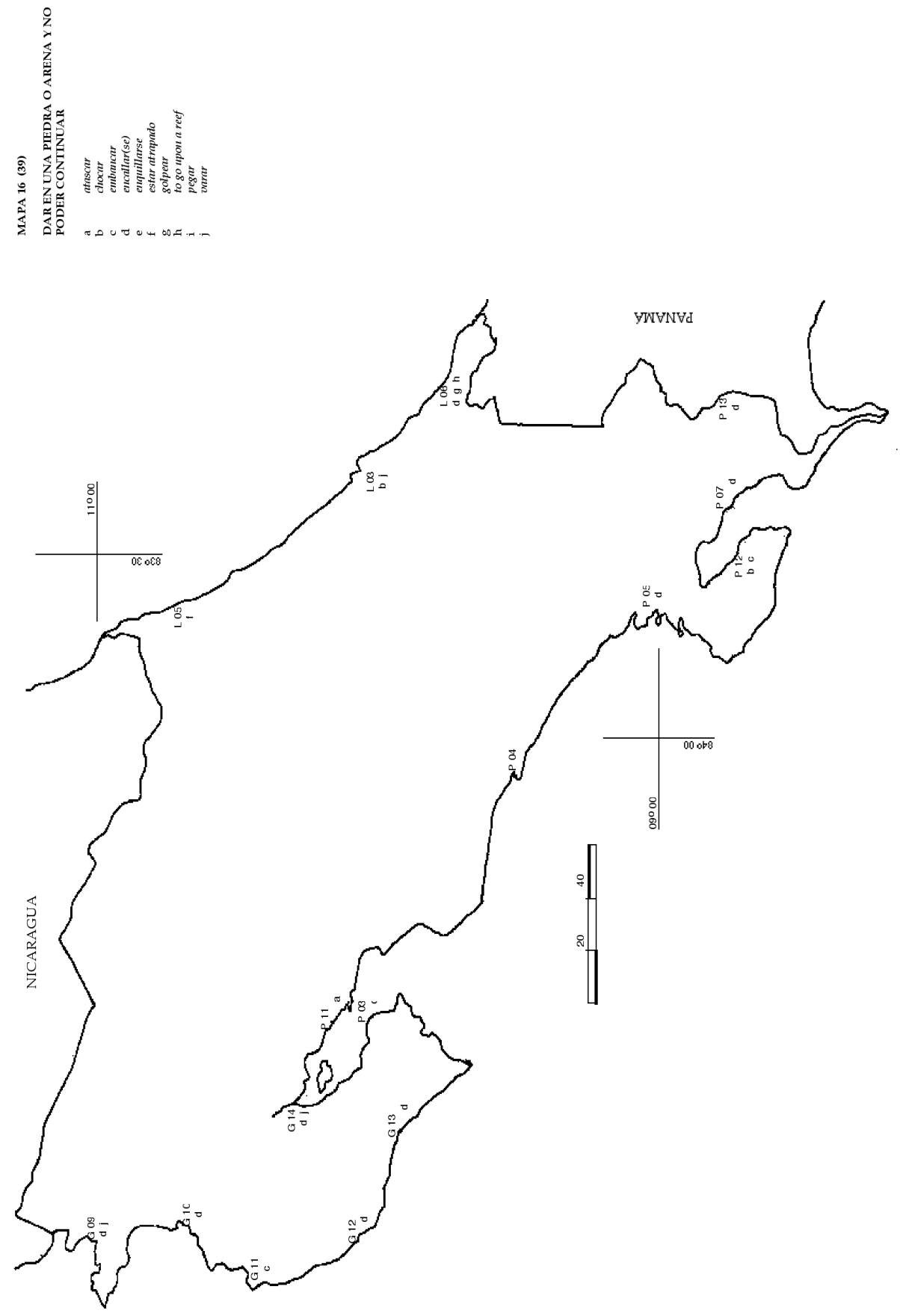

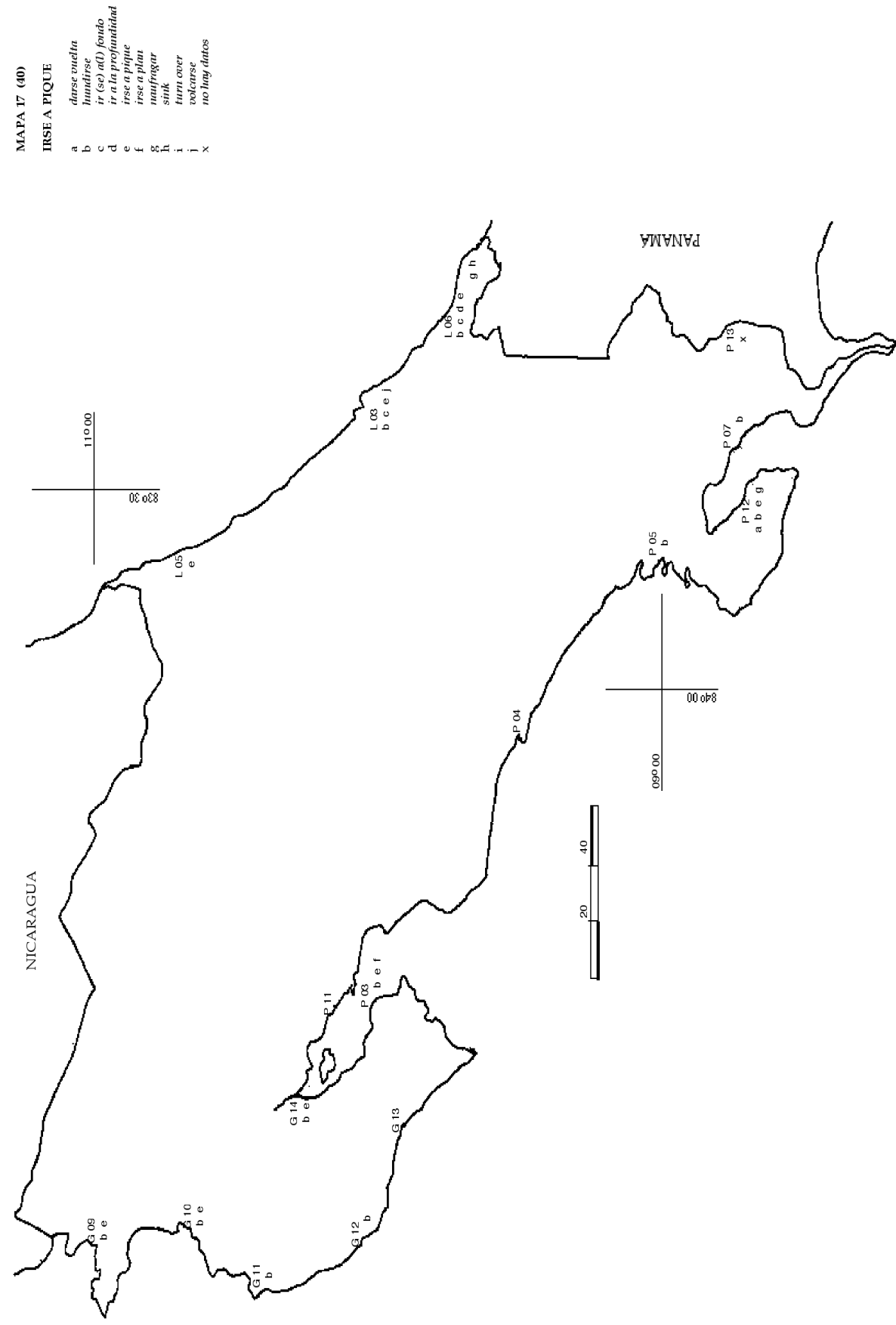


\section{Notas}

1. Tres de los mapas serán lingüístico-etnográficos.

2. La cantidad de localidades visitadas es más grande en la costa pacífica, ya que es tres veces más larga que la atlántica.

3. Con respecto a los datos personales, he sido fiel a la forma dada por los hablantes. Sin embargo, estas formas pueden esconder información, sobre todo en lo que concierne nacimiento y ocupación. "Carpintero de ribera", por ejemplo, equivale a "constructor de barcos", y "trabajo propio" a "guía de pesca", que en su lado también incluye actividades pesqueras. En algunos casos, como el de Amado Quirós (San Franciso de Coyote), se da para lugar de nacimiento el nombre del pueblo donde estaba la clínica de maternidad.

4. Dos informantes no dan este dato.

5. En Costa Rica, la educación primaria dura seis años. En la lista con los datos de los informantes se nombra también Escuela, o se señala con el año al que llegó el hablante; por ejemplo, 3er grado.

6. Se aseguraba que cumplieran el criterio indicado de natividad.

7. Excepciones son Tamarindo, Calle del Arreo y Paso Canoas, donde los encuestadores escogieron solamente a un informante por cada sitio. Aunque la información dada es más escasa que en otros lugares, es de indudable valor, ya que incrementa el material lingüístico en el que se basa esta investigación. La entrevista de Paso Canoas aumenta además el conocimiento sobre el habla de una zona fronteriza. Por estas razones, opté por incorporar también estos testimonios en el trabajo.

8. En la confección de dicho cuestionario, que toca el nivel fonético, el morfosintáctico y el léxico, Quesada Pacheco consultó cuestionarios y atlas tradicionales y más recientes. Los atlas y cuestionarios americanos (ALEC, ALESUCH, T. Navarro 1948, Alvar / Quilis 1984) y españoles (ALEA, ALEICan, ALEANAR) contribuyeron a conformar "en la medida de lo posible, un panorama en conjunto de la realidad dialectal americana y española en general” (Quesada Pacheco 1992c: 9).

9. Los números $2,45-49,68,72,77,85,86,94,95,110,114,115,117,123,126-130$ son del tipo múltiple.

10. En las individuales esta información se obtuvo mejor en el camino.

11. Para marcar que se usan distintos criterios en la organización de las palabras de los dos tipos de mapas, los etnográficos toman como punto de referencia un número en lugar de una letra.

\section{Bibliografía}

Abellán, J. L. 1972. La Idea de América. Origen y evolución. Madrid: Ediciones Istmo.

Agüero, A. 1962. El español de América y Costa Rica. San José: Atenea.

1964. "El español en Costa Rica y su atlas lingüístico". Presente y futuro de la lengua española. Madrid: OFINES. Tomo 1, 135-152. 
Akman, Haçi. Sin fecha. Kurdisk identitet. Sin editorial.

Alvar, M. (ed.). 1969. Estructuralismo, geografía lingüística y dialectología actual. Madrid: Editorial Gredos S. A.

1975. Atlas lingüístico-etnográfico de las Islas Canarias. (2 volúmenes). Gran Canaria: Ediciones del Cabildo Insular.

1977. Terminología marinera del Mediterráneo. Comisión española del A.L.E., Madrid.

1993. Estudios Canarios. Tomo II. Islas Canarias: Colección Clavijo y Fajardo.

Alvar, M., A. Llorente y G. Salvador. 1963-64. Atlas lingüístico-etnográfico de Andalucía. (5 volúmenes). Granada: Publicaciones de la Universidad de Granada.

Alvar, M., A. Llorente, T. Buesa, y E. Alvar. 1979. Atlas lingüístico-etnográfico de Aragón, Navarra y Rioja. 12 tomos. Zaragoza: Diputación Provincial, Dep. de Geografía Lingüística, Institución Fernando el Católico.

Alvar, M. y A. Quilis. 1984. Atlas lingüístico de Hispanoamérica. Cuestionario. Madrid: Instituto de Cooperación Iberoamericana.

Araya, G. (red.), C. Contreras, C. Wagner y M. Bernales. 1973. Atlas lingüístico-etnográfico del Sur de Chile. Valdivia: Instituto de Filología de la Universidad Austral de Chile y Editorial Andrés Bello.

Auer, P., A. di Luzio (ed.). 1988. Variation and Convergence. Studies in Social Dialectology. Berlin, New York: Walter de Gruyter.

Bescht, W. et al. 1982. Dialektologie. Ein Handbuch zur deutschen und allgemeinene Dialektforschung. Erster Halbband. Berlin - New York, Walter de Gruyter.

Buesa, T. y L. Florez. 1981-82. Atlas lingüístico-etnográfico de Colombia. 6 tomos. Bogotá: Instituto Caro y Cuervo.

Bugge, H. 1996. El léxico de los animales domésticos en el Valle Central y las Zonas Noroeste y Norte de Costa Rica. Tesina de Hovedfag: Universidad de Bergen.

Butler, C. 1985. Statistics in Linguistics. Nueva York: Basil Blackwell Ltd.

Cáceres, O. M. y D. Palacios. 1980. El léxico del pescador en Puerto Armuelles. David: Universidad de Panamá, Facultad de Filosofía, Letras y Educación.

Castellón, H. A. 1939. Diccionario de Nicaragüeñismos. Managua Talleres Nacionales. 
Chambers, J. K. y P. Trudgill. 1980. Dialectology. Cambridge: Cambridge University Press.

Collado, J. A. 1978. Fundamentos de Lingüística General. Madrid: Editorial Gredos.

Coseriu, E. 1985. El hombre y su lenguaje. Madrid: Editorial Gredos.

Dickeman, M. 1985. "Eliminación de la ambigüedad pronominal en el discurso del criollo limonense." Revista de Filología y Lingüística de la Universidad de Costa Rica, vol. XI (1): 119-130.

Francis, W. N. 1983. Dialectology. An introduction. Londres y Nueva York: Longman Group Limited.

Gagini, C. 1892. Diccionario de barbarismos y provincialismos de Costa Rica. San José: Tipografía Nacional.

1918. Diccionario de costarriqueñismos. San José: Imprenta Nacional.

Gellner, E. 1959. Words and Things. Londres: Victor Gollancz Ltd.

Goebl, H. (ed.). 1984. Dialectology. Bochum: Studienverlag Dr. N. Brockmeyer.

Gómez Córdoba, C. E. 1975. Vocabulario cafetero de la provincia de Cartago. Tesis de Licenciatura: Universidad de Costa Rica.

González Álvarez, L. et al. 1993. Comunidades pesquero-artesanales en Costa Rica. Heredia: Editorial de la Universidad Nacional.

Guitart, J. y J. Roy (eds.). 1980. La estructura fónica de la lengua castellana: fonología, morfología, dialectología. Barcelona: Editorial Anagrama.

Guitart, J. y J. C. Zamora. 1988. Dialectología hispanoamericana. Teoría, descripción, historia. Salamanca: Ediciones Almar.

Gulden, C. M. van der. 1994. Vocabulario nicaragüense. Managua: Editorial UCA. Colección Alternativa. Serie Habla Nicaragüense $\mathrm{N}^{\mathrm{o}} 1$.

Haber H. (ed.). 1994. Costa Rica. Insight Guides. APA Publications Ltd.

Hernández, C. et al. 1991. El español de América. Actas del III Congreso Internacional del Español de América. Valladolid, 3 a 9 de julio de 1989. Tres volúmenes. Salamanca: Junta de Castilla y León.

Herzfeld, A. 1978. "Vida o muerte del criollo limonense." Revista de Filología y Lingüística de la Universidad de Costa Rica. IV (2). 
1994. "Language and Identity: The Black Minority of Costa Rica." Revista de Filología y Lingüística de la Universidad de Costa Rica. XX (1): 113-142.

Jaberg, K. y J. Jud. 1931. Sprach- und Sachatlas des Italiens und der Südschweiz. 2 volúmenes. Zofingen: Verlagsanstalt Ringier \& Co.

Kirkpatrick, B. (comp.). 1995. The Concise Oxford Thesaurus. A Dictionary of Synonyms: Londres - Nueva York - Sydney - Toronto: BCA.

Kunnskapsforlaget. 1989. Store norske leksikon. 15 tomos. Oslo: Aschehoug \& Gyldendals forlag.

Le Guern, M. 1990. La metáfora y la metonimia. 5.a ed. Madrid: Ediciones Cátedra, S.A.

Lope Blanch, J. M. 1975. "Delimitación de las zonas dialectales de México: objetivos y problemas." Hispania 58.

1989. Estudios de lingüística hispanoamericana. México: Universidad Nacional Autónoma de México.

1990. Atlas lingüístico de México. México: El Colegio de México, Fondo de Cultura Económica.

Louis, B. 1997. El léxico del cuerpo humano en Costa Rica: Análisis dialectológico - semántico. Tesina de Hovedfag: Universidad de Bergen.

Luzio, A. di y P. Auer (ed.). 1988. Variation and Convergence. Studies in Social Dialectology. Berlín, Nueva York: Walter de Gruyter.

Lyons, John. 1991. Semantics: 1. Cambridge: Cambridge University Press.

Masís Morales, O. y E. Mora Lobo. 1985. "Las oraciones completivas en el criollo de Limón: Análisis sintáctico de un idiolecto." Revista de Filología y Lingüística de la Universidad de Costa Rica. XI (2): 111-121.

Mc Arthur, T. 1987. Longman Lexicon of Contemporary English. Londres: Longman Group UK Limited.

Meléndez, C. y Q. Duncan. 1993. El negro en Costa Rica. 10. ed. San José: Editorial Costa Rica.

Meza, H. 1980. El habla de los sabaneros liberianos y tilaranenses. Estudio léxico - semántico con anotaciones fonológicas, morfológicas y sintácticas. Tesis de Licenciatura: Universidad de Costa Rica. 
Moliner, M. 1994. Diccionario de uso del español. Dos tomos. Madrid: Gredos.

Montes Giraldo, J. J. 1970. Dialectología y Geografía Lingüística: Notas de Orientación. Bogotá: Publicaciones del Instituto Caro y Cuervo.

1973. Muestra del léxico de la pesca en Colombia. Bogotá: Publicaciones del Instituto Caro y Cuervo.

1982. Dialectología general e hispanoamericana. Orientación teórica, metodología y bibliografía. Bogotá: Instituto Caro y Cuervo.

1983b. "Habla, lengua e idioma”. Thesaurus XXXVIII: 325-339.

1993a: Motivación y creación léxica en el español de Colombia. Bogotá: Publicaciones del Instituto Caro y Cuervo.

Moreno Fernández, F. 1990. Metodología sociolingüística. Madrid: Editorial Gredos.

Muñiz Rodríguez, V. 1989. Introducción a la filosofía del lenguaje. Problemas ontológicos. Barcelona: Anthropos. Editorial del Hombre.

Navarro, T. 1948/1974. El español en Puerto Rico. Universidad de Puerto Rico: Editorial Universitaria.

Petyt, K. M. 1980. The Study of Dialect. An introduction to dialectology. Londres: The Language Library. André Deutsch Ltd.

Portilla, M. 1993. "Fonemas segmentales en el criollo inglés de Limón." En: Revista de Filología y Lingüística de la Universidad de Costa Rica. XIX (2): 89-97.

Quesada Pacheco, M. 1981. Análisis sociológico del español de San Gabriel, Monterrey y la Legua de Aserrí. Tesis de Licenciatura: Universidad de Costa Rica.

1985. Diccionario regional de los distritos de San Gabriel, Monterrey y la Legua de Aserrí. San Gabriel de Aserrí: Centro de Producciones Audiovisuales.

1991. El español de Guanacaste. San José: Editorial de la Universidad de Costa Rica.

1992a. El español en Costa Rica. San José: Editorial Fernández-Arce.

1992b. "Pequeño atlas lingüístico de Costa Rica." Revista de Filología y Lingüística de la Universidad de Costa Rica. XVIII (2): 85-190.

1992c. Atlas Lingüístico-etnográfico de Costa Rica. Cuestionario. San José: Editorial Nueva Década. 
1996. Nuevo diccionario de costarriqueñismos. Segunda ed. Cartago: Editorial Tecnológica de Costa Rica.

Real Academia Española. 1996. Diccionario de la lengua española. 21. edición. Madrid: Espasa Calpe.

Revilla, A. 1976. Panameñismos. Panamá: Roysa.

Román, J. M. 1976. El uso del español en Desamparados de Alajuela. Tesis de Licenciatura: Universidad de Costa Rica.

Roy, J. y J. Guitart (ed.). 1980. La estructura fónica de la lengua castellana. Fonología, morfología, dialectología. Barcelona: Editorial Anagrama.

Sánchez, V. 1983. Cuestionario lingüístico costarricense. San José: Editorial de la Universidad de Costa Rica.

Smith et. al. 1987. Collins Spanish - English English - Spanish Dictionary. Londres Glasgow: Collins.

The Oxford Guide to the English Language. 1983. Londres: Guild Publishing: 1981

Thomas, A. (ed.). 1988. Methods in Dialectology. Clevedon, Philadelphia: Multilingual Matters LTD.

Thompson, D. (ed.). 1995. The Concise Oxford Dictionary. Ninth edition. BCA, LondresNueva York-Sydney-Toronto: BCA.

Thun, H. 1990. Atlas lingüístico diatópico - diastrático del Uruguay. Bamberg - Stuttgart: Franz Steiner Verlag.

Vindas Chaves, F. 1971. Vocabulario del banano. Tesis de Licenciatura: Universidad de Costa Rica.

VOX. 1988. Diccionario manual ilustrado de la lengua española. Barcelona: Bibliograf S/A.

Wenker, G. 1881. Sprachatlas des Deutschen Reiches. Marburgo - Berlin.

Wilson, J. 1970. A Generative Phonological Study of Costa Rican Spanish. Tesis doctoral: Universidad de Michigan.

Wrede, F. et al. 1926. Deutscher Sprachatlas. Marburg: Elwert..

Wright, F. 1975. "Un análisis sintáctico del habla criolla de Limón.” Revista de Filología y Lingüística de la Universidad de Costa Rica. I (2). 
1982. "Problemas y métodos para la enseñanza del inglés como segunda lengua a los hablantes del Mek-a-tel-yu en la provincia de Limón." Revista de Filología y Lingüística de la Universidad de Costa Rica. VIII (1 y 2).

Zgusta Ladislav (ed.). 1980. Theory and Method in Lexicography: Western and Non - Western Perspectives. South Carolina - Columbia: Hornbeam Press, Incorporated. 